\title{
Diabetic Nephropathy: a Concise Assessment of the Causes, Risk Factors and Implications in Diabetic Patients
}

\author{
ANDRA ELENA BALCANGIU STROESCU ${ }^{1,2 *}$, MARIA DANIELA TANASESCU ${ }^{3,4}$, ALEXANDRU DIACONESCU2, LAURA RADUCU5,6, \\ DANIELA GABRIELA BALAN ${ }^{1}$, ANDRADA MIHAI ${ }^{7,8}$, MIH AELA TANASE ${ }^{9}$, IULIA IOANA STANESCU ${ }^{1,10}$, DORIN IONESCU ${ }^{3,11}$ \\ ${ }^{1}$ Carol Davila University of Medicine and Pharmacy, Faculty of Dental Medicine, Discipline of Physiology, 8 Eroii Sanitari, 050474, \\ Bucharest, Romania \\ 2 Emergency University Hospital, Department of Dialysis, 169 Splaiul Independenei, 050098, Bucharest, Romania \\ ${ }^{3}$ Carol Davila University of Medicine and Pharmacy, Faculty of Medicine, Department of Medical Semiology, Discipline of Internal \\ Medicine I and Nephrology, 8 Eroii Sanitari, 050474, Bucharest, Romania \\ ${ }^{4}$ Emergency University Hospital, Department of Nephrology, 169 Splaiul Independenei, 050098, Bucharest, Romania \\ 5 ,Carol Davila University of Medicine and Pharmacy, Faculty of Medicine, Department of Plastic and Reconstructive Microsurgery, \\ 8 Eroii Sanitari, 050474, Bucharest, Romania \\ ${ }^{6}$ Prof. Dr. Agrippa Ionescu Clinical Emergency Hospital, Department of Plastic and Reconstructive Surgery, 7 Ion Mincu, 011356 , \\ Bucharest, Romania \\ ${ }^{7}$ University of Medicine and Pharmacy Carol Davila, Faculty of Medicine, Discipline of Diabetes, Nutrition and Metabolic \\ Diseases - N. Paulescu National Institute, 5-7 Ion Movila Str., 020474, Bucharest, Romania \\ ${ }^{8}$ Prof. N. Paulescu, Bucharest, Nutrition and Metabolic Diseases National Institute of Diabetes, Nutrition and Metabolic Disease, \\ Department II of Diabetes, 5-7 Ion Movila Str., 020474, Bucharest, Romania \\ ${ }^{9}$ Carol Davila University of Medicine and Pharmacy, Faculty of Dental Medicine,Department of Pedodontics, 8 Eroii Sanitari, \\ 050474, Bucharest, Romania \\ ${ }^{10}$ Carol Davila University of Medicine and Pharmacy, Faculty of Dental Medicine Discipline of Biochemistry, 8 Eroii Sanitari, \\ 050474, Bucharest, Romania \\ ${ }^{11}$ Emergency University Hospital, 169 Splaiul Independenei, 050098, Bucharest, Romania
}

Due to the increasing number of patients in recent years, diabetes represents one of the major medical concerns. This is owed to the meaningful impact this disease has on patients' quality of life and secondary to its complications over patient survival. Diabetic nephropathy epitomises one of the complications in these patients and plays a significant role in establishing their life expectancy.

Keywords: diabetic nephropathy, albuminuria, proteinuria, arterial hypertension, ESRD

Two of the most important factors that lead to an increased incidence and prevalence of diabetes mellitus on a world scale are a higher life expectancy with an ageing population as well as a greater than before number of obese subjects. In addition, it is worth mentioning that in diabetic patients, renal involvement leads to a bigger mortality rate of cardiovascular cause [1].

\section{Experimental part}

In order to have a better understanding and implicitly, an improved management, there are numerous studies focusing on this issue [1].

\section{Resuts and discussions}

There are some differences between the two types of diabetes regarding renal involvement caused by the disease. Therefore, while the prevalence of diabetic nephropathy among patients with diabetes mellitus type 1 is ranked somewhere at $40 \%$, in patients with diabetes mellitus type 2 the prevalence is lower [1,2].

In the present, various studies in specialty literature describe the presence of a genetic component in diabetic nephropathy and despite plentiful efforts, this subject still remains shadowed by many mysteries. According to the research in the field, there have been found racial and ethnic differences. Thus, most likely secondary to some variants of APOL 1 genes, Native Americans, Mexican Americans and Afro-Americans have a higher risk to develop diabetic nephropathy compared to European-Americans. At the same time, previous studies have proved that in diabetic patients with a family history of diabetes mellitus ( $1^{\text {st }}$ grade family) and diabetic nephropathy, there is a higher risk to develop nephropathy compared to the patients without this characteristic. Research focusing on identifying the genes responsible for the occurrence of diabetic nephropathy has illustrated the important role played by glucose transporter 2 , growth factor $\beta$ and endothelial nitric oxide synthase, although the complete picture of the involved genes is still unclear [3]. Furthermore, recentstudies demonstrated that other genes such as ACE gene or CERS2 gene also have a significantrole in diabetic nephropathy development. Thus, it is considered that in patients with diabetes mellitus type 2 , gene ACE allele 1 has a protective role regarding renal involvement. Simultaneously, in these patients, the SNP component of gene CERS2 is thought to be implicated in albuminuria increase. In addition to these elements, researchers believe that the genetic polymorphism of vitamin D receptor has a notable responsibility [4].

Diabetic nephropathy is characterized by the presence of proteinuria and arterial hypertension and a registered decline of the renal function [3,5].

Proteinuria presence and its association with lesions caused by diabetes mellitus have first been described by Kimmelstiel and Wilson in 1936. Hence, the description of nodular glomerulosclerosis lesions in diabetic patients by these researchers has been associated with proteinuria and arterial hypertension. Subsequent studies and the establishment of natural evolution of diabetic nephropathy in patients with type 1 diabetes have demonstrated that these lesions represent a late stage in the disease's 
evolution. Early stages of diabetic nephropathy are characterized by glomerular hyperfiltration and minimal structural lesions caused by proteinuria and lead to manifest renal disease. Proteinuria is produced by glomerular lesions that increase the permeability of the basal glomerular membrane for macromolecules. Numerous studies describe the important part played by angiotensinogen in this process through the induced systemic vasoconstriction conducting to a higher arteriolar resistance at the glomerular level and to an increased pressure in the glomerular capillaries. This last aspect is at the bottom of a higher capillary permeability with a reduction in the filtration area and a stimulated cellular proliferation and also the induction of the fibrogenesis process [5].

Diabetic nephropathy is characterized by important structural lesions, such as podocytes loss and the thickening of the basal glomerular membrane due to an increased collagen synthesis [5]. The mutation in the podocytes genes also contributes to the occurrence of structural lesions that subsequently lead to urinary loss of proteins in patients with diabetic nephropathy. Eloquent examples for these situations are the loss of the protein associated with CD-2 or the alterations suffered by the transmembrane cytoskeletal proteins, nephrine expression reduction [57]. In addition to the glomerular modifications, renal interstitium and tubular alterations can also be found in diabetic nephropathy. The studies show that several clinical correlations can be found depending of the lesions' extension. Thus, interstitial lesions and their broadening are strongly connected to a higher level of albuminuria while interstitial fibrosis is correlated with renal function $[5,8]$.

In the present, since the focus is more and more on the genetic determination of diabetic nephropathy, researchers consider that SNP component of gene CERS 2 plays an important part in albuminuria [4,9]. Besides proteinuria, diabetic renal disease is also characterized by renal function decline [3,5]. According to presentstudies, SNP component of gene CERS2 is associated with albuminuria increment and less so with glomerular filtration rate decrease [9].

Thus, in diabetic patients with renal involvement, early functional alterations lead to albuminuria occurrence and once the structural alterations advance, it goes from microalbuminuria to the stage of macroalbuminuria. In the latter stage, in absence of specific treatment (antiproteinuria), in some patients a decrease in glomerular filtration rate can be observed over time. However, in some patients, renal function decline can be noticed at the same time with proteinuria occurrence just like in other cases a decrease in glomerular filtration rate can be observed without proteinuria. In this last case the factors that determine the decline of the renal function are unknown, but according to some studies, this situation is encountered more frequently in type 1 diabetes [2].

Next to the presence of proteinuria, diabetic nephropathy is also characterized by the presence of arterial hypertension, as shown by epidemiologic studies that indicate that more than $50 \%$ of the diabetic patients are diagnosed with high blood pressure.

Hydrosaline retention, the activation of the reninangiotensin-aldosterone (RAAS) system and of the sympathetic nervous system (SNS), as well as oxidative stress and endothelial dysfunction are importantfactors in the occurrence of arterial hypertension in diabetic patients with renal disease $[10,11]$. Maintaining the blood pressure under $130 / 80 \mathrm{mmHg}$ represents a therapeutic approach with a major impact on nephropathy progression slowdown. Additionally, numerous studies suggest that a good management of arterial pressure in patients with diabetic nephropathy and proteinuria determines the reduction of the protein quantity lost in urine daily [12]. Keeping in mind the physiopathological bases of arterial hypertension and proteinuria in patients with diabetic patients with renal involvement, it is justified to administer either ACEI or ARB and the administration becomes mandatory when the patient has macroalbuminuria and an estimated GFR lower than $60 \mathrm{~mL} / \mathrm{min}$ [13]. The researchers wanted to assess if a better blood pressure control and systolic arterial pressure values under 120 $\mathrm{mmHg}$ bring additional benefits compared to a higher target for the systolic blood pressure. Regarding the cardiovascular involvement, no net benefits have been found when low arterial pressure levels were maintained. However, a significant albuminuria decrease was displayed. In the present, KDOQI recommends maintaining the arterial pressure under $130 / 80 \mathrm{mmHg}$ in diabetic patients. Compared to this suggested target, the JNC8

Table 1

DIABETIC NEPHROPATHY - RISK AND PROGRESSION FACTORS

\begin{tabular}{|l|l|}
\hline Diabetic nephropathy - Risk factors & Diabetic nephropathy - Progression factors \\
\hline UNMODYFYBLE FACTORS & Genetic factors \\
Genetic factors & Ethnic factors \\
Ethnic factors & Glomerular hyperfiltration \\
Glomerular hyperfiltration & Important metabolic imbalance (increased level of HbA1c) \\
Increased evolvement duration of the diabetes & Increased systolic or mean arterial pressure \\
Old age & High albumin urinary excretion \\
Female sex & Renal function decline \\
Presence of retinopathy diagnosis & Presence of the same time of other microvascular \\
MODYFYALE FACTORS & complications (retinopathy, neuropathy) \\
Albuminuria in large quantity & Diabetes evolvement duration \\
Increased levels of glycaemia & Old age of the subject \\
High levels for arterial pressure & Male sex \\
Dyslipidemia & High BMI \\
Obesity & Smoking \\
Smoking & Serum levels of some constants: low hemoglobin, \\
Oxidative stress & hypercholesterolemia, hypertriglyceridemia, low vitamin D, hyperuricemia \\
Subclinical inflammation & Arterial pulse wave speed \\
& Systemic inflammation \\
& Endothelial dysfunction \\
& Tubular dysfunction markers \\
\hline
\end{tabular}




\begin{tabular}{|cc|}
\hline & Sudden increase in proteinuria \\
\hline & Early debut of nephrotic syndrome \\
\hline & $\bullet \quad$ Hematuria \\
\hline & Atypical alteration of the biohumoral constants (E.g. hypercalcemia) \\
\hline & \\
\hline
\end{tabular}

Table 2

ELEMENTS THAT SUGGEST NON-DIABETIC RENAL INVOLVEMENT proposes a higher targetfor the arterial pressure in diabetic patients with renal involvement - <140/90mmHg [3].

Renal involvement in diabetic patients also includes the decline of the renal function next to proteinuria and arterial hypertension. Modern evaluation of the renal function under different formulae is presented as eGFR [14]. Another factor contributing to the progression of diabetic nephropathy is the presence of diabetic retinopathy. The latter is a prognostic factor for ESRD occurrence, especially in type 2 diabetes $[15,16]$. At the same time, the presence of a high number of comorbidities in this category of patients characterizes an additional risk factor for renal disease progression $[15,17]$. ESRD development, more frequent in type 2 diabetes patients at the present time, constitutes an important risk factor for increased mortality [15].

Thus, the association of diabetic nephropathy with a multitude of complications justifies the clinicians' interest to establish all the risk factors that lead to its occurrence and, once diagnosed, to the determination of the progression risk factors towards advanced stages of the disease. These factors are summarized in table $1[18,19]$.

Taking into consideration the characteristics of diabetic renal disease, in some cases the diagnosis is difficult due to the absence of some of the items or the presence of new ones. For this kind of situations the identification of factors that could indicate a non-diabetic renal involvement has been suggested (these factors can be found in table 2) [5].

\section{Conclusions}

The correct approach of the diabetic patient with renal involvement is recommended to be integrative, individualized. There will be evaluated - glycemic control (HbAlc, hypoglycemia occurrence), - renal function at that moment (eGFR, albuminuria), - presence of chronic complications of diabetic renal disease that targets iron status, mineral and bone disorders. Among the proposed tools for the evaluation of the diabetic patient with renal involvement, we can also include comorbidity assessment (arterial hypertension, dyslipidemia), as well as the presence of infection or obstruction of the urinary tract. Depending on the presence or absence of these items, the optimal treatment is chosen for the evaluated patient. Insulin, SGLTi and GLP analogs are preferred to control the glycemic level. Thus, insulin therapy has good protein anabolic effects and represents the recommended treatment for hyperkalemia, as well as in cases of significant metabolic imbalance. Furthermore, SLGT2i are therapeutic agents that contribute to the decrease of albuminuria, butalso in lowering the systolic blood pressure. Once the decline of the renal function is registered, insulin represents the optimal therapeutic solution [20]. The newest diabetes mellitus management guide is the one published by ADA 2018. According to this guide, in diabetic patients with renal involvement, the administration of
SGLT2 inhibitors had produced a decrease in cardiovascular involvement caused by atherosclerosis, but also had, certain benefits regarding diabetic renal disease progression. On the other hand, in this antidiabetic class of medicines, a reduction of the effect of decreasing glycemic levels can be observed with renal function decline. The administration of these medicines depends on eGFR because at the present time it is notallowed to administered if eGFR $<45 \mathrm{~mL} / \mathrm{min} / 1.73 \mathrm{~m}^{2}$. The association of this class of antidiabetic medicines with diuretics for hypertension treatment and with ACE inhibitors/ARBs enhances the risk of acute renal injury. Meanwhile, the same guide specifies that the administration of DPP-4 inhibitors requires dosage adjustment in accordance with the patient's renal function. The only exception from this rule is represented by linagliptin because the renal excretion for this member of the medicine class is minimum [21].

An association between significant oxidative stress and endothelial dysfunction can be observed in diabetic patients [22]. Moreover, diabetic renal disease is also characterized by the existence of important oxidative stress. Recent studies show that in these patients, vitamin E administration has certain benefits over glycemic control and at the same time, over renal protein loss [23].

\section{References}

1.MORA-FERNANDEZ C., DOMINGUEZ-PIMENTEL V., MUROS DE FUENTES, M., GORRIZ, J.L, MARTINEZ-CASTELAO A., NAVARROGONZALEZ J.F. J Physiol., 592, No. 18, 2014, p: 3997-4012

2. BAKRISG.L, RICHARD J GLASSOCK R.J ., NATHAN D.M., UpToDate, last updated Feb 28, 2017, https://www.uptodate.com/contents/ overview-of-diabetic-nephropathy accessed April 2018.

3. UMANATH K, LEWIS J,B, American J ournal of Kidney Diseases, Volume 71, No. 6, 2018, p. 884-895

4.TI M, XUE L, YIN Q, SHAO S, CAI J, ZHANG W, J Clin Exp Nephrol, No. 2, doi: 10.21767/2472-5056.100029.

5.FOGGENSTEINER L, MULROY S , JOHN FIRTH J, x J R Soc Med., Volume 94, No. 5, 2001, p: 210-217.

6.KIM J M, WU H, GREEN G, ET AL, Science, No. 300, 2003, p:12981300.

7.LANGHAM RG, KELLY DJ, COX AJ, ET AL, Diabetologia, No. 45, 2002, p:1572-1576.

8.GILBERT RE, COPPER ME, Kidney Int, No.56, 1999, p:16271637.Kausik Umanath

9.SHIFFMAN D., PARE G, OBERBAUE R, LOUIE JZ, ROWLAND CM, DEVLIN J J, J OHANNES F. MANN J F,. MCQUEEN MJ , Plos, https://doi.org/ 10.1371/journal.pone.0106631 accessed April 2018. .

10.NAZAR CMJ. J ournal of Nephropharmacology. Vol. 3, No.2, 2014, p:49-55.

11.VAN BUREN PN, TOTO R. Advances in chronic kidney disease, Vol. 18. No.1, 2011, p:28-41.

12.GRASSI G, MANCIA G,. NILSSON PM, Diabetes Care, 39, Supplement No.2, 2016, p: S228-S233 
13.STERNLICHT H. · BAKRIS G.L. Affiliation Celera, Alameda, CA, United States of America Blood Purif, No.41, 2016, p:139-143/* Affiliation Population Health Research Institute, Hamilton Health Sciences and McMaster University, Hamilton, Ontario, Canada

14. DABLA PK, World J Diabetes., 1, No.2, 2010, p: 48-56

15.*** https://emedicine.medscape.com/article/238946-overview \#a5 accessed April 2018.

16.ZHANG J, WANG Y, LI L, ET AL. Ren Fail., 40, No.1, 2018, p:243-51. 17. JIANG R, LAW E, ZHOU Z, YANG H, WU EQ, SEIFELDIN R., Diabetes Ther. 2018.

18.TZIOMALOS K, ATHYROS VG, Rev Diabet Stud, No. 12, 2015, p:110118

19.RADCLIFFE NJ, SEAH J, CLARKE M, MACISAAC RJ, JERUMS G, EKINCI El, J Diabetes Investig., 8, No. 1, 2017, p: 6-18.
20.KALRA S, SAHAY M, DHANDA D, SAHAY R., Indian J Endocr Metab No.22, 2018 p:167-8.

21.DAVIES MJ, D'ALESSIO DA, FRADKIN J, KERNAN WN, MATHIEU C, MINGRONE G, ROSSING P, TSAPAS A, WEXLER DJ, BUSE JB, A consensus report by the American Diabetes Association (ADA) and the European Association for the Study of Diabetes (EASD), Diabetes Care 2018 Sep; dci180033. https://doi.org/10.2337/dci18-0033

22.ANISIA, I A, CANTEMIR, A, ANTIOCH, I, BALMUS, I.M, COJOCARU, S, GARDIKIOTIS, R, LUCA, A, FILIP, M-A, ABABEI, D.C, ZAMFIR, C.L, Rev. Chim.(Bucharest), 68, no. 2, 2017, p:350-353.

23.HALIGA RE, BUTCOVAN D, OBOROCEANU T, PINZARIU AC, COSTAN VV, CRAUCIUC DV, SINDILAR A, LUPUSORU RV, MOCANU V, Rev. Chim. (Bucharest), 68, no. 7, 2017, p. 1449-1452

Manuscript received: 8.05.2018 